\title{
"SOMOS CRIATURAS DE LA LÓGICA Y NO DEL SILENCIO": LA UNIDAD PROPOSICIONAL SEGÚN ALBERTO MORETTI
}

\author{
"We are Creatures of Logic and not of Silence": \\ Propositional Unity according to Alberto Moretti
}

\author{
Silvia Carolina Scotto ${ }^{a}$ \\ https://orcid.org/0000-0002-2013-8539 \\ carolina.scotto@unc.edu.ar \\ ${ }^{a}$ Instituto de Humanidades - Facultad de Filosofía y Humanidades - Universidad \\ Nacional de Córdoba - Consejo Nacional de Investigaciones Científicas y Técnicas, \\ Córdoba, Argentina.
}

\section{Resumen}

En este comentario me refiero a algunos aspectos de la propuesta de Moretti acerca del problema de la unidad proposicional, basada en su interpretación de las ideas de Frege y Davidson. La misma sostiene que, más allá de sus evidentes diferencias, ambas concepciones del lenguaje y del significado oracional, en tanto atribuyen al lenguaje una función esencialmente representacional, comparten una manera de entender la primacía de la aserción por sobre otros tipos de emisiones lingüísticas. A su vez, según Moretti, las aserciones reflejan la importancia del lenguaje para entender tanto los rasgos constitutivos de las capacidades cognoscitivas humanas como también sus límites. Después de examinar la interpretación de Moretti, formulo un conjunto de preguntas y objeciones acerca de los presupuestos y compromisos teóricos del enfoque fregeano-davidsoniano que se desprenden de diversos enfoques alternativos (cognitivos, pragmáticos y semánticos). Esos enfoques pueden confluir en una visión de los sistemas lingüísticos que considera más básicos a sus usos comunicativos que a sus funciones representacionales. Así, la unidad proposicional podría ser mejor explicada como un rasgo derivado de los actos cognitivos de los hablantes (incluidas sus intenciones comunicativas). Y los contenidos semánticos de las expresiones lingüísticas resultarían determinados, finalmente, por los factores que intervienen en la realización de los actos de habla de los que forman parte, sin otorgar primacía a los actos de habla asertivos, y menos aún, a sus productos, las oraciones declarativas.

Palabras clave: Unidad proposicional; Frege; Davidson; Aserción; Actos de habla.

${ }^{1}$ The power of words, Brice Parain, citado por Jolley (2007). 


\begin{abstract}
In this comment I refer to some aspects of Moretti's proposal about the problem of propositional unity, based on his interpretation of Frege's and Davidson's ideas. It maintains that, beyond their obvious differences, both conceptions of language and sentence meaning, as much as they ascribe an essentially representational function to language, share a way of understanding the primacy of assertion over all the other types of linguistic utterances. In turn, according to Moretti, assertions reflect the importance of language to understand the constitutive features of human cognitive capacities as well as their limits. After examining Moretti's interpretation, I articulate a set of questions and objections to the theoretical presuppositions and commitments of the Fregean-Davidsonian approach which arise from various alternative proposals (cognitive, pragmatic, and semantic). These proposals can converge in a vision of linguistic systems that considers their communicative uses to be more basic than their representational functions. Thus, the propositional unity could be better explained as a feature derived from the speaker's cognitive acts (including their communicative intentions). And the semantic contents of linguistic expressions would ultimately be determined by the factors that intervene in the performance of speech acts, without giving primacy to assertions, and even less to their products, namely, declarative sentences.
\end{abstract}

Key words: Propositional Unity; Frege; Davidson; Assertion; Speech Acts.

En este trabajo voy a compartir algunas reflexiones motivadas por la lectura de "La unidad proposicional" (UP) (2014) de Alberto Moretti ${ }^{2}$. La "trama" de las ideas allí expuesta puede comprenderse mejor a la luz de escritos previos o posteriores, tales como "Lógica y semántica" (LS) (2006), "Concepciones de la lógica" (CL) (2010), "La lógica y la trama de las cosas" (LTC) (2016), entre otros, a los cuales me referiré ocasionalmente. Esas lecturas reunidas hacen más nítida una "urdimbre" (para emplear otra noción holística del mismo estilo que aquellas a las que nuestro autor recurre con frecuencia) de conceptos, ideas y argumentos. Me refiero al modo de articulación que sostiene esos escritos, los que, sospecho, son sólo un reflejo esquivo de la urdimbre de los pensamientos que expresan. Dicho desde la perspectiva inversa, el planteo de cada cuestión, interpretación o propuesta forma parte de un "tejido" muy elaborado, lo que hace difícil examinarlas por partes,

\footnotetext{
${ }^{2}$ Alberto Moretti es una figura intelectual importante en nuestra comunidad filosófica. Reconocemos en él a un filósofo, a un cierto tipo de filósofo, y no sólo a un lúcido intérprete de las ideas filosóficas de otros. Por esa razón, participar en una publicación dedicada a reflexiones o comentarios críticos sobre su producción filosófica es un motivo de satisfacción tanto como un desafío que agradezco a los colegas responsables de llevar adelante la iniciativa.
} 
analizarlas o desmenuzarlas en sus elementos, sin "desnaturalizar" (valga la ironía en este caso) su intención, sin llevar su pensamiento hacia donde no quiere ir. En sintonía con estas consideraciones preliminares, me gustaría destacar, además, un rasgo de la escritura filosófica de Moretti, que es a la vez infrecuente y atractivo en estas épocas de producción académica estandarizada. Me refiero al intento de elaborar un "idioma" filosófico propio, casi despojado de referencias a la literatura secundaria y a sus jergas barrocas. También a su estilo de pensamiento (incluyendo el que se expresa singularmente en aquellos pensamientos que son continuaciones o desarrollos originales de los pensamientos de otros filósofos), y al diseño y empleo de conceptos, metáforas y analogías en los que no siempre es posible discernir quién habla: si es Frege, si es Davidson (sólo por mencionar a los dos héroes más importantes de UP), o si es el propio Moretti. Es el caso que, muchas veces, hablan un poco todos ellos, aunque de una nueva manera. Volveré sobre esta cuestión al final.

UP hace honor a la pregunta platónica del Sofista (y otros textos) acerca de cuál es la diferencia entre una mera lista o secuencia de expresiones (nombres o predicados) y una oración. Se lee en el Sofista:

[...] 'marcha', 'corre', 'duerme', y todos los demás verbos, que representan acciones, si se pronuncian en fila, no formarán nunca un discurso... Lo mismo si se dice: 'león', 'ciervo', 'caballo' y todos los nombres que se dan a los que ejecutan las acciones, se habrán colocado unos enseguida de otros, pero no resultará discurso ... Si se los mezcla, ellos concuerdan, y hay discurso, es decir, una primera combinación; el primero y el más pequeño de los discursos. (S, 262A)

La cuestión que Platón expuso tan limpiamente se identifica en la literatura filosófica como el problema de la unidad de la proposición, y fue tratado mucho tiempo después por Frege, Russell y el primer Wittgenstein con herramientas de análisis más sofisticadas que las de Platón (aunque, como se verá, Ryle tiene algo que decir en favor de las herramientas de Platón) $)^{3}$. El problema consiste en explicar cómo las partes significativas (o constituyentes) de una proposición se

${ }^{3}$ También Davidson (2005) resaltó los méritos del planteo del problema en Platón, por haber advertido que la solución tenía que integrar tres aspectos: que el juicio o la oración deben constituir una unidad para que pueda ser verdadero o falso; que toda oración debe contener dos elementos: un verbo y un elemento que designe el objeto del que se juzga o afirma algo, y que estos elementos deben tener funciones diferentes (p. 82). 
combinan entre sí para producir una totalidad significativa unificada, distinguiéndose de una mera serie, concatenación o agregado de ellas. Dicho de otra forma, mencionar, nombrar o referir a un objeto (o a varios) y a una propiedad (o a varias) no es suficiente para afirmar que ese objeto tiene esa propiedad. La cuestión puede reformularse así: cuál es la diferencia semántica entre nombres y predicados, e incluso asumiendo que la noción de nombre y la función semántica de nombrar parecieran más claras, el problema consiste en explicar la naturaleza de la predicación, y con ello, la naturaleza de la aserción. En este último sentido, según Soames (2017), el problema no sería tanto explicar la unidad compleja que se logra al relacionar distintos elementos, en este caso, significados o expresiones lingüísticas, sino en explicar cómo se logra que esa unidad represente a algo como siendo de cierta manera. Así, en sus palabras: "El problema es explicar la intencionalidad de las proposiciones" (p. 182). Agreguemos ahora que cuando algo se afirma, la proposición (y la oración que la expresa) ${ }^{4}$ puede ser o bien verdadera 0 bien falsa, es decir, es portadora (primaria) de valores de verdad.

Cabe señalar que se han ofrecido formulaciones alternativas, aunque no equivalentes, del problema de la unidad proposicional, en parte relacionadas con la adopción de una u otra concepción de las proposiciones. Por otro lado, como se ha advertido, sólo para algunas de ellas el problema no parece suscitarse (Speaks 2019). Se ha señalado también que bajo este tópico sería correcto identificar a un conjunto bien diferenciado de problemas. Estos problemas guardan relación no sólo con la noción de proposición que se adopte, sino también con los variados papeles atribuidos a las proposiciones como entidades teóricas, vgr. las proposiciones permitirían explicar los contenidos codificados en los signos lingüísticos, así como la comprensión de esos contenidos; la propiedad de las oraciones que las expresan de poseer valores de verdad y diversos atributos modales; ellas serían los objetos de las actitudes proposicionales y de los objetos referidos por las oraciones de adscripción

${ }^{4} \mathrm{El}$ concepto de proposición es un concepto técnico y también teórico del que se han ofrecido diferentes criterios de identidad y diferentes concepciones sobre su naturaleza. Cuando el contexto lo permita, me referiré indistintamente a proposiciones y oraciones, asumiendo una noción teóricamente neutral respecto a las primeras: las proposiciones serían los significados expresados por las oraciones declarativas. Algunos autores argumentan que debiera prescindirse de ellas y plantear el problema de la unidad sólo al nivel del lenguaje, más precisamente, en referencia a las oraciones declarativas, y mutatis mutandis, a las demás oraciones significativas (cfr. Kemp 2011, p. 7; Bronzo 2017, pp. 750-753). Esta opción puede deberse, a su vez, a diferentes razones, por ejemplo, Davidson (1967) argumenta que las proposiciones no tienen ninguna utilidad teórica. 
de tales actitudes -las cláusulas 'que'-, etc. (véase King 2014). Por estas y otras razones, el problema de explicar cómo las proposiciones logran constituirse a partir de los elementos que las componen, se convirtió en un problema multidimensional, con implicaciones metafísicas, epistemológicas y semánticas (también lógicas), o al menos, en un ramillete de problemas del que pueden darse versiones diferentes en cada uno de esos ámbitos. Esta es una razón, entre otras, del desacuerdo y la dispersión reinantes sobre el tema.

En UP se examinan dos enfoques (o programas) acerca del problema formulado por Platón: el de Frege y el más reciente de Davidson. La elección no es gratuita, ya que, según Moretti, ambos "han determinado la mayoría de las reflexiones sobre el lenguaje" (UP, p. 63). Pero además porque, más allá de sus notables diferencias, ambas propuestas serían convergentes. En primer lugar, comentaré algunos rasgos salientes de cada una de ellas, siguiendo la interpretación desarrollada por Moretti y cotejándola, en ocasiones, con interpretaciones alternativas. Luego, formularé un conjunto de preguntas u objeciones que se desprenden de enfoques alternativos acerca de los presupuestos y compromisos teóricos del enfoque fregeano-davidsoniano defendido por Moretti.

\section{La solución fregeana}

La propuesta de Frege ejemplificó un tipo de solución al problema de la UP, en los siguientes sentidos. En primer lugar, porque se enmarcó en una concepción del "lenguaje como medio para pensar el mundo" (en adelante: LM) (UP, p. 63), es decir, en una concepción representacional del lenguaje que intenta explicar el significado proposicional "apelando a la estructura del mundo" (LTC, p. 13). En este sentido, se trataría de una solución basada en los lazos del lenguaje con el mundo. En segundo lugar, porque se trataría de un tipo de solución explicativa, en particular, una que pretende dar cuenta de cómo los nombres y los predicados pueden producir la unidad del significado proposicional invocando elementos distintos de los puramente lógico-lingüísticos con los que éstos se relacionan y en los que encuentran su fundamento: objetos particulares y universales (propiedades y relaciones).

Tanto aquella concepción del lenguaje como este carácter explicativo de la solución al problema de la unidad proposicional, ambos consistentes entre sí, y un tercer rasgo derivado de ellos, a saber, que el problema esté planteado para Frege (así como para Platón) respecto al lenguaje que Moretti llama "discurso con pretensiones cognoscitivas", son importantes para entender cómo pueden resultar, finalmente, con- 
vergentes con una visión tan diferente en otros aspectos como la de Davidson. En efecto, el problema está referido a los que ambos filósofos consideran los casos básicos a explicar o elucidar: las aserciones. Para ambos, la aserción sería el tipo de emisión lingüística más básica respecto de la cual hay que explicar cómo las oraciones obtienen la unidad de contenido que las distingue de la mera agregación de sus componentes. Y la razón de ello es que, según afirma Moretti, las aserciones reflejan "una operación fundamental de nuestro pensar consistente en identificar un ítem individual y describirlo de modo general" (UP, p. 64). Esta operación básica del pensamiento requiere la combinación de dos elementos de diverso tipo y función, referencia singular y predicación, la que se expresaría claramente en los enunciados asertivos. Ahora bien, para que la explicación tenga el alcance que aparentemente se pretende, otras operaciones del pensamiento y otras formas de discurso, es decir, los enunciados asertivos complejos y otros tipos de emisiones lingüísticas y de actos de habla, deberían poder explicarse de modo similar, incorporando otras dimensiones que no serían estrictamente semánticas en el sentido señalado (vgr. estados psicológicos, intenciones comunicativas y actos de habla y diversas características específicamente lingüísticas). Volveremos sobre esta cuestión más abajo.

Ahora bien, como también afirma Moretti, la explicación fregeana de la unidad proposicional está proporcionada por la semántica, es decir, "sin suponer sobre la estructura de la realidad nada más que lo que el análisis a priori de las nociones semánticas básicas arroje” (UP, p. 65). Por lo tanto, aunque apela a una "estructura del mundo" en la que el análisis semántico encuentra un fundamento, ofrece una explicación que no está apoyada en una reflexión ontológica independiente y complementaria, sino en la suposición, o, como afirma Moretti, en el desideratum, de que la "estructura sintáctica" (y en general, la lógica subyacente que estructura el lenguaje) "refleje la estructura de la realidad" (UP, p. 64). Sin alejarnos mucho de Frege, es decir, en el mismo corazón de la primera filosofía analítica, esa fue también la visión del Tractatus: "La lógica llena el mundo; los límites del mundo son también sus límites" (5.61). La lógica "llena" también el lenguaje y determina sus límites. ${ }^{5}$ Otra versión aún más sugerente de esta misma idea fue expresada así: "La lógica cuida de sí misma" (Notebooks, 1914-16, p. 2),

\footnotetext{
${ }^{5}$ Aprovecho estas referencias a Wittgenstein (aunque no "a cualquiera de ellos", como dice con cierta ironía Moretti, sino al del Tractatus) para expresar mi desconcierto por su casi completa ausencia en los escritos que estamos comentando, excepto de modo marginal e incluso meramente adjetivo (por ejemplo, en UP, p. 69, y en CL, p. 176).
} 
que puede interpretarse como la tesis de que “... la lógica no puede mirar a la izquierda para pedir ayuda a la psicología ni mirar a la derecha para pedir ayuda a la metafísica. Debe ser auto-suficiente" (Jolley 2007, p. 27) . Entonces, "el análisis a priori de las nociones semánticas básicas" que se proponía realizar Frege, al revelar la "incomparable esencia del lenguaje", revelaría también "el orden a priori del mundo". Esto es posible porque el orden a priori o la estructura lógica es común al lenguaje (y al pensamiento) y al mundo. Retomo esta cuestión acerca del carácter y el papel de la lógica más abajo.

Algunos estudiosos de la obra de Frege advierten, sin embargo, que no es del todo claro qué carácter tuvo su estrategia para lidiar con el problema de la unidad de la proposición, si revistió un carácter explicativo, como propone Moretti (junto a muchos otros intérpretes) o si, en cambio, siguió una estrategia disolutoria, como sugieren las interpretaciones a las que me referiré enseguida. Tampoco los intérpretes coinciden respecto del papel que tuvo la distinción entre dos tipos de entidades, objetos y conceptos: si fue formulada principalmente para resolver el problema de la unidad de la proposición (Gaskin 2008), o si, en cambio, fue elaborada sobre todo para aclarar el diferente funcionamiento lógico de los nombres propios y los conceptos o expresiones funcionales (Bronzo 2017). Una manera en la que pueden converger estas alternativas sería la siguiente: así como los universales necesitan instanciarse en los particulares, del mismo modo los predicados sólo se completan cuando se combinan con los nombres. De ese modo, el carácter incompleto de los predicados, basado en el carácter incompleto de los universales, explicaría su función distintiva. Según la mayor parte de los intérpretes, esta sería la "respuesta oficial" de Frege al problema de la unidad proposicional (Bronzo 2017) y está avalada por sus propias palabras:

[...] Los objetos y los conceptos son fundamentalmente diferentes y no pueden estar uno por el otro. Y lo mismo sucede con las correspondientes palabras o signos. Los nombres propios no pueden realmente ser usados como predicados. Donde podría parecer que lo

\footnotetext{
${ }^{6}$ Esta idea sobre la relación entre lógica, lenguaje y mundo es presentada en Investigaciones Filosóficas con un tono (auto)crítico: "El pensamiento está rodeado de una aureola. - Su esencia, la lógica, presenta un orden, y precisamente el orden $a$ priori del mundo, esto es, el orden de las posibilidades que tienen que ser comunes a mundo y pensamiento... Estamos bajo la ilusión de que lo peculiar, lo profundo, lo que es esencial en nuestra investigación reside en que trata de captar la incomparable esencia del lenguaje... Este orden es un super-orden entre - por así decirlo— superconceptos" (§ 97 y ss.)
} 
son, mirando con más detenimiento encontramos que el sentido es tal que ellos sólo forman parte del predicado: los conceptos no pueden estar en las mismas relaciones que los objetos. No sería falso, sino imposible pensar que operan de ese modo (Frege 1892a pp. 174-5, mi traducción).

Una complicación adicional de esta "solución" surge cuando se advierte que mediante los términos generales no sólo atribuimos propiedades a los objetos, sino que también podemos referirnos a ellos. En este último rol, los predicados podrían asimilarse a los nombres, pero en tal caso una proposición no sería otra cosa que una lista de nombres (considerado el problema en su dimensión metafísica, sólo estaríamos ante una agregación o co-existencia de dos entidades, un objeto y una propiedad, no relacionadas entre sí). Los problemas y paradojas que suscita esta equiparación de las funciones referenciales de nombres y predicados son conocidos. Para resolverlos, o bien se puede apelar a la diferente naturaleza metafísica de lo nombrado por cada uno (la solución de Frege), o bien se puede eliminar la dimensión metafísica de los universales y con ella la función referencial de los predicados (como propuso Quine), diferenciando más claramente las funciones semánticas de nombres y predicados. Así, los predicados no nombran nada, sino que sólo se aplican a los objetos nombrados y, por lo tanto, son o no satisfechos por ellos. Esta salida nominalista (sin recurrir a universales), será también la de Davidson: los predicados mantienen con los objetos nombrados una relación de satisfacción, y la oración en la que se predica algo de un individuo será verdadera en el caso que el referente del nombre sea uno de los individuos que satisfacen el predicado. Sin embargo, como veremos, esa no será la solución davidsoniana al problema de la unidad proposicional: en vez de tomar como básicas a las relaciones de satisfacción, Davidson tomará como básica la propiedad de las oraciones de ser verdaderas, y ello no requerirá correspondencia con nada mundano.

Por otra parte, algunos intérpretes han atribuido un papel preponderante al Principio del Contexto (PC) en la "solución" fregeana del problema, interpretándolo como la "contraparte metodológica" del reconocimiento de la unidad proposicional (Jolley 2007, p. 36) ${ }^{7}$. Así, cuando

\footnotetext{
${ }^{7}$ En rigor, según la interpretación de Jolley, tanto el Principio del Contexto, como otros dos principios fregeanos, serían conjuntamente necesarios para dar cuenta del problema de la unidad proposicional, a saber: nunca se debe confundir una investigación lógica con una investigación psicológica y nunca se debe confundir "objeto" y "concepto". Los tres principios, considerados en forma conjunta, permitirían reconocer (y no explicar) la "unidad de la proposición" (cfr. Jolley 2007, p. 36, n. 15 y 97 y ss.):
} 
Frege recomienda que "no preguntes por el significado de ninguna expresión fuera o independientemente del contexto de la proposición en la que aparece", estaría minando las premisas que hacen posible formular el problema de la unidad proposicional, y de ese modo, más que resolverlo estaría disolviéndolo (Hylton 2005, p. 177). Las nociones de concepto y objeto no pueden comprenderse independientemente una de la otra, así "...Frege presupone la noción de juicio como fundamental..." (ibidem). Es decir, de acuerdo con una interpretación fuerte del PC, Frege estaría negando que ambos tipos de componentes sub-oracionales, nombres y predicados, puedan ser significativos independientemente de algún contexto proposicional. Dicho de otra forma, la unidad de la proposición sería una noción primitiva que no requeriría explicación. En el mismo sentido, Jolley (2007) afirma que esta es la posición tanto del Tractatus en 3.314 y las Investigaciones acerca de la unidad de los "juegos de lenguaje", como la de Frege: "Frege no tiene ninguna explicación que ofrecer de la unidad del juicio: es el proto-fenómeno, la cosa primaria, lo que es dado" (p. 100). La interpretación así llamada "primitivista" de la unidad proposicional, más allá de su adecuación hermenéutica a las ideas de Frege, tiene notables defensores recientes y algunas variantes. ${ }^{9}$

A esta interpretación se ha objetado que si el PC fuera comprendido del modo descripto, estaría en conflicto con otras tesis fregeanas, especialmente con la naturaleza composicional del pensamiento y el lenguaje, por lo cual sería razonable interpretarlo de un modo menos fuerte (ver Bronzo 2017). Según el Principio de Composicionalidad, los significados de las oraciones están determinados por los significados de sus partes y por el modo como se combinan entre sí. Una solución a esta tensión entre ambos principios, originada en las ideas de Dummett (1973) -“en el orden de la explicación, el sentido de una oración es primario, pero en el orden del reconocimiento, el sentido de una palabra es primario" (p. 4), sería comprender que ambos operan en diferentes niveles: mientras las oraciones serían metafísicamente previas a las

\footnotetext{
"Los tres principios de Frege son los imperativos metodológicos requeridos por su reconocimiento de la unidad del juicio" (p. 98).

${ }^{8}$ Parece más claro atribuir a Wittgenstein una estrategia disolutoria, tanto en el Tractatus como en las Investigaciones, que a Frege. Lo primero está sugerido por el análisis de Zalabardo (2017). Haremos referencia luego a algunas ideas "disolventes" de las Investigaciones Filosóficas.

${ }^{9}$ Merricks (2015), por ejemplo, desarrolla una teoría de la naturaleza de las proposiciones según la cual “... cada proposición representa esencial y primitivamente a las cosas como siendo de una cierta manera” (p. 195), en contraste con las explicaciones de su naturaleza y unidad basadas en una cierta relación entre sus constituyentes y su estructura, o basadas en las actividades cognitivas de los agentes.
} 
palabras, las palabras pueden ser reconocidas independientemente, cuando aparecen en diferentes combinaciones. Una manera algo diferente de entender la compatibilidad entre ambos principios sería la siguiente: mientras las oraciones expresan significados que dependen de manera específica de cada una de las palabras que las componen (y de la estructura sintáctica que las combina entre sí), las palabras, fuera del contexto de una u otra oración, dependen genéricamente de los significados de (algún conjunto) de oraciones en las que podrían aparecen (cfr. García-Carpintero 2010, p. 284).

Ahora bien, de acuerdo con el Principio de Composicionalidad, los componentes sub-oracionales que se combinan para formar totalidades significativas deberían tener un significado que se pueda al menos abstraer de los significados que tienen en las oraciones que efectivamente integran, de lo contrario no se podrían explicar aquellas propiedades para las cuales el principio ha sido propuesto (productividad, sistematicidad, aprendibilidad). Ryle (1960) sugirió que esta posibilidad estaba contenida en el modelo alfabético o "modelo letra-sílaba" aplicado por Platón al problema de la unidad proposicional en sus diálogos tardíos. Según el mismo, las consonantes y las vocales en las sílabas pronunciadas o en las unidades fonéticas proferidas son análogas a los nombres y los predicados en las oraciones. Así: "Para que una oración exprese una aserción se debe unir una expresión nominativa con un verbo conjugado -de alguna manera como en una sílaba una consonante debe unirse con una vocal" (p. 67) (yo destaco). Para Platón, las consonantes son análogas a los nombres y las vocales a los predicados: las consonantes no se pueden pronunciar si no están acompañadas por una vocal, así como los nombres no tienen uso si no van acompañados de un predicado. De ese modo: "Nombres y verbos como consonantes $\mathrm{y}$ vocales, pueden variar independientemente, pero no pueden funcionar por sí mismos" (p. 68) ${ }^{10}$. El interés de la analogía, estriba en que,

${ }^{10}$ En su análisis del modelo de letras y sílabas, Ryle subraya la importancia de situar la analogía al nivel del lenguaje hablado y no de los signos escritos. Los caracteres escritos representan a los sonidos, vocales o consonantes, y son "átomos gráficos", en tanto sus elementos pueden inscribirse separadamente y recombinarse con otros. De acuerdo a la analogía, en cambio, los sonidos representan la contribución semántica que los nombres y los predicados hacen al significado oracional. La semejanza que apoya la analogía reside en que ninguna de estas entidades son átomos, sonoros o semánticos, respectivamente. Es decir, "los fonemas no son átomos fonéticos" de "moléculas fonéticas". Así, por ejemplo, un monosílabo fonético no está compuesto por partes que puedan separarse fonéticamente, puesto que las consonantes (la mayoría de ellas) carecen de sonidos pronunciables independientemente del sonido silábico completo, es decir, necesitan unirse a una vocal para tener existencia sonora. Así, las 
sostiene Ryle, "(L)os significados de las palabras o los conceptos no son componentes de la proposición sino diferencias proposicionales. Son distinguibles, pero no separables; se pueden abstraer, pero no extraer." (p. 61) (Yo destaco). Es decir, respecto de los elementos sub-oracionales, no hay que confundir la "abstracción”, que es posible y “...requiere advertir la constancia de algo a través de rangos de variación en sus configuraciones", de la "extracción", que es imposible (p. 64). De este modo, ni los nombres ni los predicados expresan "átomos" o "unidades de pensamiento" separables, sino que sólo expresan semejanzas y diferencias de pensamiento que se pueden abstraer de los pensamientos completos, parcialmente similares y parcialmente diferentes con respecto a otros pensamientos en los que aparecen.

Glock (2010) da un paso más porque adopta un enfoque similar del tipo “arriba-abajo", que va desde las oraciones enteras a sus componentes por un proceso de abstracción, pero propone complementarlo con una perspectiva de la génesis de las proposiciones y de las oraciones estructuradas que va en la dirección inversa, de "abajo-arriba". Esta última, sin embargo, no sigue el camino de la "composición" desde los conceptos hacia las proposiciones y las oraciones, sino que comienza también con oraciones, pero con aquellas carentes de estructura: "oraciones holofrásticas" (y "holocreencias") y va desde ellas hacia las proposiciones y las oraciones estructuradas. Esta segunda vía permitiría explicar la naturaleza de los contenidos más primitivos o menos complejos, sorteando "el imperativo de analizar sintácticamente" sus "componentes" conceptuales, aunque podamos luego describirlos aproximadamente mediante posibles emisiones. ${ }^{11}$

consonantes en los sonidos verbales deberían verse más que como elementos separables (como los caracteres), como rasgos o aspectos que asemejan y diferencian entre sí a los sonidos lingüísticos totales en los que ocurren, las palabras habladas. Y las vocales, como las expresiones predicativas, aunque son indispensables, son criaturas incompletas para Platón, semejantes a las expresiones funcionales de Frege. La analogía es interesante porque ayuda a comprender la unidad estructural de elementos funcionalmente diferentes y también su recombinabilidad. Ryle hace una interpretación exquisita de la aplicación de este modelo de letras y sílabas en diversos textos tardíos de Platón, a este y otros problemas filosóficos, y concluye que: "Su admirable modelo, del que Frege careció, de los elementos fonéticos en las sílabas, le permitió a Platón explicar más lúcidamente que Frege la noción de variabilidad-independiente-sin separabilidad de los significados de las partes de las oraciones." (p. 74).

${ }^{11}$ Sugiero que esta última "solución" permite afrontar el problema inverso al de la unidad proposicional, el (pseudo)-problema de "la búsqueda de precisión proposicional" (cfr. Dennett 1998, pp. 41 y ss.), en tanto descansa en el mismo supuesto que aquel: todo pensamiento es proposicional y las proposiciones son estructuras compuestas por determinados elementos constituyentes combinados entre sí de ciertas maneras. Se 
Sobre estas bases podría entenderse el PC del siguiente modo: mientras los elementos sub-oracionales sólo tienen significado en el contexto oracional, ellos mismos también pueden tener significado en otros contextos oracionales. Dicho de otra forma, las palabras significativas actualizan potencialidades semánticas establecidas por las convenciones lingüísticas sólo cuando son usadas en oraciones significativas. En consecuencia, el significado de cada uno de esos elementos tiene que ser suficientemente estable para que puedan significar (aproximadamente) lo mismo en nuevos contextos oracionales, y también pueda explicarse nuestra capacidad para entender nuevas oraciones a partir de nombres y predicados que ya hemos comprendido previamente en otras oraciones. Bajo esta interpretación de cómo entender ambos principios, el Principio del Contexto y el Principio de Composicionalidad, el problema de la unidad proposicional se desvanece. Bronzo (2017) explora minuciosamente la viabilidad de esta interpretación en Frege.

Sin embargo, para algunos intérpretes, también para Moretti, no es en el PC donde hay que buscar la respuesta fregeana, sino, como decíamos, en la distinción y la asimetría entre dos tipos diferentes de entidades: las entidades no saturadas o incompletas, los conceptos, y las entidades saturadas o completas, los objetos. Como afirma Frege, "No todas las partes de un pensamiento pueden ser completas; al menos una debe ser no saturada o predicativa; de otro modo no se unirían" (Frege 1892a, p. 193, el destacado es mío). Las proposiciones, por su parte, requieren de la combinación de dos tipos semánticos diferentes: nombres propios y expresiones predicativas. Entonces, la unidad de la proposición se explicaría por "la saturación de algo no saturado" (Frege 1923-26, p. 390). Finalmente, es también posible afirmar que ambas "soluciones", atribuibles a Frege bajo ciertas interpretaciones, están en una cierta tensión irresuelta: mientras la distinción funcional no saturado/saturado permitiría explicar la unidad proposicional, es incompatible tanto con una interpretación fuerte como con una más débil del Principio del Contexto ${ }^{12}$, que más bien apuntaría a disolver

trata del problema suscitado en muchos contextos de atribución intencional ordinaria, más dramáticamente aún en los casos de atribución de contenidos a los pensamientos de criaturas no lingüísticas o cuasi-lingüísticas al no poder precisar qué proposiciones es legítimo atribuir. No obstante, aunque los criterios de identidad de esos contenidos no posean el "soberbio poder de resolución de nuestro lenguaje", el problema se disuelve en la medida en que podamos encontrar maneras de describirlos en él.

${ }^{12}$ Bronzo (2017) desarrolla la tesis de esta tensión irresuelta en Frege, incluso bajo una interpretación más laxa del principio del contexto. Pero sostiene, además, que la estrategia basada en la distinción entre entidades saturadas y no saturadas no tendría el propósito primario de explicar la unidad proposicional, sino que sería 
el problema de la unidad proposicional. En cualquier interpretación, está claro, finalmente, que Frege encara el problema sin apelar a las intenciones de los hablantes ni a los actos de emisión oracional.

\section{La solución davidsoniana}

Veamos ahora cómo presenta Moretti la solución davidsoniana al problema de la unidad proposicional. En primer lugar, esta es tributaria de un enfoque diferente del lenguaje. Se trata de la caracterización del lenguaje como un sistema de interpretaciones (IL) o, en términos de Moretti, como la relación entre una "trama potencialmente infinita de oraciones" y la capacidad humana de comprender... un plexo ilimitado de proferencias" (LS, p. 36). La pregunta es ahora ¿cómo somos capaces de interpretar las emisiones lingüísticas de otro, y en general, ¿cómo podemos interpretar su lenguaje? Es decir, se busca entender la unidad proposicional en "la comprensión mutua entre los hablantes" (UP, p. 66), o apelando sólo a "la estructura del intercambio lingüístico" (LTC, p. 13). Y esa estructura no "revela(n) ni impone nada sobre una presunta estructura del mundo externo" (LTC, p. 13). Bajo esta perspectiva interpretativista, el problema de la unidad proposicional, y en general, el del significado oracional, es enmarcado en el problema de cómo es posible la práctica lingüística intersubjetiva, porque se entiende que este problema es "conceptualmente anterior" a cualquier otra manera de abordarlo. Entonces una oración posee significado, y es, por lo tanto, una oración y no una mera lista de palabras (o peor aún, una sarta de ruidos), a condición de formar parte de un sistema mayor de estructuras similares, o, como le gusta decir a Moretti, de una "trama de significados" o un sistema lingüístico (UP, p. 66). A su vez, un sistema lingüístico es tal en la medida en que sea comprendido y empleado por una comunidad lingüística. Como puede verse, tanto por el estilo de pregunta (¿cómo es posible...?), como por el marco en el que esta es formulada (la práctica lingüística), no se busca explicar el significado oracional relacionando sus elementos con ítems en el mundo (una relación que ha dejado ser

parte de un argumento trascendental no del todo elaborado según el cual, supuesta la unidad proposicional, ésta puede justificarse aceptando que es el resultado de una combinación entre entidades saturadas y no saturadas, cada una con diferentes roles lógicos. Si esta fuera la interpretación más ajustada del papel de la distinción mencionada, finalmente Frege estaría aún más cerca de la estrategia de Davidson: ambos suponen la unidad proposicional y sólo intentarían justificarla mediante el uso instrumental de algunas nociones más básicas y con la ayuda de una argumentación trascendental. 
fundamental para explicar el significado (cfr. UP, p. 66)), sino que se procura "legitimar conceptualmente la auto-adscripción"13 (UP, p. 68; LTC, p. 14), para cada hablante, de una capacidad interpretativa ilimitada. En este sentido, el problema de la unidad proposicional se disuelve en el problema de la comprensión intersubjetiva por medio del lenguaje.

En cualquier caso, una teoría de la interpretación es (entre otras cosas) una teoría del significado y explicitar las condiciones conceptuales de posibilidad de la interpretación se realiza mostrando de qué modo es posible atribuir significados a las emisiones lingüísticas de un hablante, esto es, atribuyendo significados a las oraciones emitidas, y no a elementos sub-oracionales que luego deberían combinarse apropiadamente. Esa explicación es posible, para Davidson, tomando como punto de apoyo el concepto de "verdad". Ningún otro contexto sería más básico que éste para explicar el significado, y este contexto, el de la interpretación del habla de otros, requiere lidiar con oraciones, o mejor, con actos de emisión de oraciones, y estos presuponen el dominio de un concepto primitivo de "verdad". El significado, entonces, será una propiedad básica de las oraciones y no de los componentes sub-oracionales, lo que también requiere mostrar de qué modo los conceptos lógicos y la "forma lógica" generan las verdades lógicas que los hablantes aceptan, y de ese modo estructuran/revelan la "trama de significados" que articulan oraciones con oraciones del conjunto potencialmente infinito que se quiere interpretar. Otra diferencia importante con Frege aquí es que las proposiciones no resultan, para Davidson, herramientas teóricas útiles en absoluto. Las oraciones emitidas ya no expresan proposiciones, sino que su significado está dado por las cláusulas que las emparejan con otras oraciones, las oraciones del intérprete, mediante el expediente del predicado "es verdadero".

${ }^{13}$ Como sabemos, Davidson adopta la perspectiva del intérprete para elaborar su teoría del significado. Ahora bien, Moretti afirma que Davidson intenta con su teoría "legitimar la auto-adscripción" de esa competencia interpretativa. Esa manera de formular el objetivo de la teoría davidsoniana puede generar confusión, puesto que parece girar el foco de la tercera a la primera persona: el propósito de explicar o justificar esa competencia consiste en mostrar cómo es posible y en qué consiste la "hetero-adscripción" de significados y pensamientos a otros, manifiesta en la fluidez de la práctica lingüística (un aspecto en el que Davidson sigue a Quine). En cuanto a la propia competencia interpretativa, como veremos enseguida, para Davidson es un factum y la condición de posibilidad de la atribución de significados. Quizás Moretti se refiere a lo que Speaks (2014) caracteriza como propio de una teoría derivada del significado: explicar la competencia semántica con un lenguaje por medio de la competencia semántica con otro. 
Hay que enfatizar, además, que Davidson toma a la interpretación como un factum (LTC, p. 14; LS, p. 37), porque antes toma como un factum la existencia de comunidades lingüísticas involucradas en prácticas discursivas que requieren comprensión intersubjetiva. Esta "primera palabra" es también importante para Moretti: el lenguaje existe en las comunidades que lo hablan, no independientemente de ellas. Y en este punto ve a Davidson como habiendo corrido el punto de partida a un lugar más correcto que aquél desde donde comienza Frege. Ese punto de partida son las criaturas que usan el lenguaje:

Nada se consideraría una oración y el concepto de verdad no tendría aplicación si no hubiera criaturas que usaran oraciones emitiendo o inscribiendo instanciaciones de ellas. Cualquier completa explicación del concepto de verdad debe relacionarlo con el intercambio lingüístico real. (Davidson 2005, p. 36, mi traducción)

Moretti, por su parte, identifica a ese punto de partida como la "estructura intérpretes-cosas-relaciones" (UP, p. 68). Incluso más: "El habla, la capacidad de intercambio lingüístico, es una pre-condición de nuestro modo de ser y, por ende, de nuestro modo característico de comprender: teorizar" (LS, p. 31). También: "Somos esos que hablamos y que a veces producimos y evaluamos razonamientos. Y esta producción y evaluación nos impresiona como una manera de ser, fundamental para ser quienes somos" (CL, p. 163). Es interesante señalar que ambas tesis: (a) el intercambio lingüístico y la capacidad que lo hace posible son constitutivos de nuestro modo de ser y de pensar y (b) esa capacidad requiere teorizar, tomadas conjuntamente, expresan el núcleo de la perspectiva davidsoniana acerca del lenguaje.

Ahora bien, debe señalarse que el intento de mostrar cómo podría explicarse esa competencia no depende de atribuir al intérprete y al hablante ordinarios la realización de un esfuerzo teórico semejante al del propio filósofo cuando procura explicitar los principios y reglas y explicar cómo podrían derivarse los teoremas verdaderos que dan cuenta de esa competencia: "La teoría describe las condiciones bajo las cuales una emisión de un hablante es verdadera, y no dice directamente nada acerca de lo que el hablante sabe" (Davidson, 2005, p. 52). Se asume, en cambio, que la interpretación se apoya en una "captación pre-teórica" o en una pre-comprensión del predicado 'es verdadero' tomado como un predicado primitivo, a partir del cual es posible interpretar el habla de otros, o más específicamente, un número indefinido de oraciones de su lenguaje. Dicho de otra forma "todo lo que tendría que requerirse 
de una teoría de la verdad para un hablante es que sea tal que, si un intérprete tuviera conocimiento proposicional explícito de la teoría, conocería las condiciones de verdad de las emisiones del hablante" (p. 53). Por otra parte, dado que el significado de cada oración quedará establecido mediante la asignación del predicado 'es verdadero', se reconocerá preeminencia al significado oracional respecto del papel semántico que tienen los componentes sub-oracionales, lo que será un aspecto fundamental del tipo de solución davidsoniana. Además, tanto la noción de verdad como otras nociones semánticas, como bien señala Moretti, tendrán un valor instrumental y no sustantivo, en tanto son empleadas para apoyar la explicación del significado oracional (LTC, p. 15). Así, la solución davidsoniana, a diferencia de la fregeana, presupone que comprender el significado de una oración es comprender, potencialmente, un número infinito de otras oraciones de ese lenguaje, lo que a su vez presupone, pragmáticamente, la propia competencia lingüístico-interpretativa.

Ahora bien, Davidson creía que era posible y necesario elaborar una teoría sistemática sobre la semántica de los lenguajes naturales para mostrar cómo es posible disolver el problema de la unidad proposicional. En los últimos escritos recogidos en Truth and Predication (2005) admite que el problema no concierne sólo a la filosofía del lenguaje sino también a la filosofía de la mente y a la metafísica, aunque su propuesta para resolverlo se restringe a la semántica. Otra restricción, pero esta vez de alcance, será la que explícitamente establece Davidson para una teoría semántica: sólo puede explicar las emisiones con significados literales, por lo cual un "aspecto esencial" de las emisiones lingüísticas queda fuera de su alcance: la fuerza ilocucionaria. Aunque los hablantes y los intérpretes, bajo ciertas condiciones, consiguen detectar las ironías, los chistes, las metáforas, etc., esta capacidad no puede explicarse por medio de una teoría semántica: "Creo que hay buenas razones para pensar que nada como una teoría seria es posible en relación con esta dimensión del lenguaje." (2005, pp. 53-4, n. 6). En cambio, las oraciones no declarativas, como aquellas que sirven para expresar valoraciones, y otras como imperativos o interrogativos, aunque pueden no ser ni verdaderas ni falsas, están relacionadas lógica y evidencialmente con aquellas que sí tienen condiciones de verdad. Entonces, “...es improbable que la semántica de tales oraciones pueda darse sin apelar a sus relaciones con oraciones para las cuales conocemos las condiciones de verdad ${ }^{14}$. Davidson conclu-

\footnotetext{
14 "Esto es obvio en el caso de los imperativos y los interrogativos. Entendemos un imperativo si y sólo si conocemos bajo qué condiciones lo que ordena o establece
} 
ye que: "La verdad y la predicación van juntas; ninguna oración carece de un predicado, y la mayoría de las oraciones, si no todas, son entendidas sólo si sus condiciones de verdad, o las condiciones de verdad de oraciones estrechamente relacionadas, son conocidas." (p. 124) (yo destaco). De esta manera, el significado basado en condiciones de verdad alcanzaría, directa o indirectamente, a todo tipo de oraciones y aun cuando sea una propiedad de las emisiones lingüísticas y el fruto de operaciones de interpretación, sólo deja afuera las intenciones comunicativas y la fuerza con la cual dichas emisiones son realizadas por los hablantes. Ahora bien, ¿es satisfactoria una teoría del significado que no puede explicar lo que muchas emisiones lingüísticas significan en virtud de las intenciones comunicativas de los hablantes y la intervención de factores contextuales?

Asumiendo que ambas concepciones, la de Frege y la de Davidson, a pesar de sus importantes diferencias, podrían resultar no sólo afines sino de algún modo convergentes -tal es la interpretación que propone Moretti-, voy a formular en lo que sigue algunas preguntas y a señalar algunas alternativas teóricas disponibles para la reflexión en torno al problema de la unidad proposicional. Para ello, me serviré de referencias clásicas y otras más o menos recientes que muestran el interés de esas alternativas. El sentido de las preguntas que siguen asume, siguiendo la interpretación de Moretti, que hay líneas de confluencia bien justificadas que llevan más o menos naturalmente de Frege a Davidson.

\section{Algo más que "hablar de cosas"}

Aunque ambas concepciones difieren en la estrategia para su solución, consideran que el problema de la unidad proposicional es "un problema fundamental de la reflexión filosófica sobre el lenguaje” (UP, p. $63)$, y que es susceptible de una explicación unitaria, sea o no puramente semántica. Una objeción a este tipo de enfoques, precisamente, apunta al hecho que presentan el problema como un único problema general, esto es, aplicable a todos los lenguajes, y que pretendan obtener una explicación también general y, además, suficientemente informativa. La objeción consiste en sostener que ambos desiderata lo convierten en un problema intratable. Por ejemplo, quienes adoptan un enfoque lingüístico, es decir, no proposicionalista sino oracionalista, pueden argumentar que “...el rango de dispositivos por medio de los cuales tal

es obedecido. Las posibles respuestas a una pregunta son oraciones relacionadas sintáctica y semánticamente a la pregunta, y las respuestas tienen un valor de verdad, incluso si las preguntas no lo tienen." (2005, p. 124). 
estructura puede ser indicada es irreconciliablemente diverso" entre las lenguas (Peacock, 2011, p. 412, 417) ${ }^{15}$. Ahora bien, no es claro si esa estrategia pluralista para abordar el problema, relativa a lenguajes o familias de lenguajes, sólo impone un grado de especificación o relatividad de la explicación a cada lenguaje a la manera de Davidson, donde la asignación de significados es neutral a la diversidad lingüística, o si podría apuntar a las diferencias entre las lenguas en tanto reflejarían y reproducirían modos de pensamiento estructuralmente diferentes.

Desde un ángulo más positivo, las concepciones LM y LI difieren de otras concepciones del lenguaje que ven el problema de la unidad proposicional como un problema más bien derivado que básico. Una versión general de esta idea la ofreció Strawson (1970) al contrastar dos enfoques diferentes acerca del lenguaje: uno basado en las condiciones de verdad de los enunciados, el de la semántica formal, y otro basado en las interacciones comunicativas. En el primero confluyen claramente Frege y Davidson, en el segundo los filósofos de orientación pragmática: Wittgenstein, Austin, Grice ${ }^{16}$. Según Strawson, los héroes representativos de cada uno de ellos habrían librado un "combate homérico", no obstante, ambos enfoques podrían ser complementarios siempre que se considere al segundo de ellos como el más fundamental. Una razón que apoyaría esta evaluación es que el habla es más fundamental que cualquier otro uso del lenguaje y "hablar es una clase de acción" (Gibson 2004, p. 149).

Este giro hacia un enfoque pragmático del problema ha sido desarrollado, de diversas maneras teóricamente fructíferas, por distintos filósofos. Grice (1957), por ejemplo, ha mostrado cómo los significados convencionales de las expresiones lingüísticas emitidas no bastan para comprender los contenidos pragmáticamente comunicados. El significado de las oraciones asertivas usualmente no es su significado literal,

${ }^{15}$ Peacock (2011) se refiere, a modo de ejemplo, a las lenguas muy flexivas (como el latín), que utilizan muchas variaciones en la terminación de las palabras y no sólo el orden para indicar diferencias en la estructura del contenido, y obligan a relativizar algunas explicaciones de la unidad proposicional reflejadas sólo por la estructura sintáctica, sugiriendo que todas las expresiones y no sólo los predicados, juegan un rol en la explicación de la unidad. Wittgenstein señaló el mismo punto, mediante el ejemplo de una oración del latín, "ambulo" (Tractatus, 4.032), de una única palabra, que no obstante expresa un contenido estructurado.

${ }^{16}$ Wikforss (2016) cuestiona la interpretación de Strawson sobre el tipo de "combate" que enfrentaría a Davidson con Wittgenstein en relación con ambos tipos de enfoques acerca del lenguaje, identificando afinidades importantes, aunque no al nivel de sus respectivas explicaciones (o descripciones) semánticas, sino a nivel metasemántico o fundamental. 
sino cierta relación entre este, las intenciones del hablante, el contexto de la emisión y las reglas que rigen los intercambios conversacionales. Gibson (2004), por su parte, desarrolló una propuesta pragmática específica basada en que "...la unidad de la oración reside en la realización del hablante de un cierto acto en cierto contexto... Lo que explica el acto de decir explica la unidad de la oración” (p. 140). Según Gibson la explicación debe basarse en relaciones de dependencia causal y en las nociones "pragmáticas" (no "sintácticas" ni "metafísicas") de sujeto y predicado oracional (p. 145).

Con un enfoque más intuitivo, es decir, más cercano a una reconstrucción de la competencia semántica ordinaria que el que ofrecen los enfoques del estilo Frege-Davidson, y que preserva, además, la utilidad teórica de la noción de proposición, se ha propuesto reformular el problema de la unidad de la proposición desde la perspectiva cognitiva del sujeto que realiza el acto proposicional de pensar algo como teniendo cierta propiedad. Con palabras de Soames (2017): “...uno debe reconocer que predicar y, por lo tanto, representar, es algo que los agentes hacen. Las propiedades no predican por sí mismas nada” (p. 185). De ese modo, tampoco el problema de la unidad de la proposición sería intrínseco a ellas, sino que es dependiente de los eventos cognitivos intencionales de quienes piensan en ellas (Soames 2012). "En vez de que los juicios y las aserciones hereden condiciones de verdad de las proposiciones, las proposiciones heredan condiciones de verdad de los juicios y aserciones particulares. Nuestros actos de juzgar o aseverar son los portadores primarios de condiciones de verdad, y las proposiciones toman sus condiciones de verdad de estas acciones" (Hanks, 2017, p. 239) ${ }^{17}$. El problema de la unidad proposicional se resolvería, entonces, explicando la naturaleza de los actos cognitivos involucrados en distintos tipos de juicios y tratando a las proposiciones como “...tipos de acciones representacionales (que) usamos para caracterizar, clasificar e individuar nuestras acciones mentales y verbales" (Hanks, 2017, p. 241). De ese modo, esta perspectiva lograría desmitificar la metafísica y la epistemología de las proposiciones y explicar sus capacidades representacionales en términos de las capacidades de los actos cognitivos (Speaks, 2019).

${ }^{17}$ Expresado con cierta ironía, el extremo antipsicologismo fregeano “...nos conduce a ver a los sujetos humanos no como productores de representaciones sino como consumidores de ellas. No generamos representaciones cuando formamos juicios o hacemos aserciones. Más bien tomamos variadas actitudes hacia representaciones pre-existentes cuando formamos actitudes, o presentamos [put forward] estas representaciones de variadas maneras al realizar actos de habla. Según la visión fregeana, pensar o hablar es hacer algo con una proposición" (Hanks, 2017, p. 238). 
En una variante diferente del mismo enfoque cognitivo, las proposiciones podrían ser caracterizadas como "constructos lógicos" derivados de las prácticas y habilidades de las criaturas que piensan conceptualmente, y los conceptos, en tanto constituyentes de las proposiciones, como abstracciones realizadas a partir del uso que las palabras tienen en las oraciones (Glock 2010). Por otra parte, su contenido puede inferirse de las oraciones que las expresan, sin que se requiera que estas posean partes completamente articuladas que se combinan de ciertas maneras. Dada su utilidad teórica, las proposiciones deberían mantenerse, aunque bajo una caracterización minimalista y derivada, es decir, descartando el "proposicionalismo" y el "modelo composicional" (el así llamado "modelo building-block') clásicamente asociado a él, que proporciona el formato clásico de nuestro problema (véase Glock 2010, pp. 81 y ss.) ${ }^{18}$.

Por otra parte, las llamadas 'teorías contextualistas del significado' también han mostrado de qué maneras una variedad de elementos pragmáticos (near-side pragmatic effects) deben ser incorporados al contenido de las oraciones emitidas, porque algunas expresiones que las componen son semánticamente "incompletas" y, por lo tanto, también lo son las oraciones de las que forman parten. Es decir que para asignar significado a muchas emisiones lingüísticas no basta con condiciones de verdad: se requiere incorporar factores contextuales vinculados con los escenarios de emisión, los cuales podrían determinar asignaciones de significado completamente diferentes a las mismas expresiones oracionales. Desde esta perspectiva, se requeriría incluso una noción de condiciones pragmáticas y no puramente semánticas de verdad, para determinar no sólo lo que es implicado, sino también lo que es dicho (Orlando 2015). Así, la unidad proposicional en relación con muchas (o todas) las emisiones lingüísticas, sólo podría explicarse acabadamente en la medida que se incorporen distintos factores contextuales de carácter pragmático para determinar su significado. Tampoco desde esta perspectiva sería

${ }^{18}$ Glock sugiere que una fuente de estímulos para el modelo composicional de las proposiciones es el lenguaje: "Lo que parece dar sentido al discurso de partes y todos en el caso de las proposiciones o pensamientos es el hecho de que las expresiones lingüísticas de los pensamientos -es decir, las oraciones- tienen componentes es decir, palabras... Aunque nuestros criterios de identidad para proposiciones no son los mismos que nuestros criterios para la identidad de oraciones, podemos identificar las primeras solamente porque podemos identificar las últimas” (p. 82). En el mismo sentido, creo que el carácter secuencial del lenguaje y, adicionalmente, el carácter discreto de la escritura, que son propios de la expresión lingüística de las proposiciones, sugieren la prioridad y la distintividad de los elementos que componen las diferentes oraciones en las que ellos podrían participar. Sin embargo, lo que estos elementos significan en ellas sería cognitivamente más básico. 
posible identificar nuestro problema al nivel de las proposiciones, sino que se requeriría hacer referencia a los actos de habla en los que estas adoptan una u otra expresión lingüística particular y reciben una u otra interpretación, dependiendo de la información relativa a los contextos de uso. El problema de la unidad proposicional se transforma en el problema de explicar el contenido semántico-pragmático de las emisiones lingüísticas en el marco de los actos comunicativos.

Ahora bien, establecer si a partir de los enfoques mencionados es posible ofrecer una explicación o elucidación general del significado lingüístico y/o de la comprensión intersubjetiva por medio del lenguaje que no dependa sólo de las condiciones veritativas entendidas al modo clásico, es decir, que incorpore los elementos que intervienen en la determinación del significado de las expresiones lingüísticas en los actos cognitivos y de habla, obligaría a desarrollar argumentos positivos y negativos adicionales a los ofrecidos por los modelos clásicos. Se puede leer una rápida y temprana referencia a ellos en "Semántica tarskiana..." (1992) de Moretti, la cual, sin embargo, no alcanza a constituir una respuesta acabada. Es interesante, sin embargo, que en aquél escrito temprano se sostenía que las teorías basadas en condiciones de verdad no pretendían ofrecer "una explicación fundamental del fenómeno de la significatividad lingüística" (p. 20), sino que su objetivo era más "modesto". Esta restricción de alcance de las teorías Frege-Davidson no parece mantenerse en los escritos posteriores a los que nos hemos referido en este trabajo, en los que se hace referencia genérica al lenguaje humano, y, en todo caso, no pareciera igualmente aplicable a Frege que a Davidson (cfr. UP, p. 66-67).

Moretti podría tener buenos argumentos para rechazar el intento de elaborar concepciones más abarcativas de la "significatividad lingüística”, argumentando, por ejemplo, que modifican el explanandum de la teoría y, con ello, su interés para específicos fines teóricos. Esto es lo que Frege quiso hacer al deslindar sus preocupaciones teóricas: separó los actos de expresar oraciones de los contenidos expresados, la función asertórica de otras funciones satisfechas por otros actos de habla y los elementos básicos que determinan el contenido semántico de otros elementos expresivos (como los "matices" y el "énfasis" o la "coloración" de las palabras). Pero también es posible que Moretti considere a las teorías semánticas no clásicas o bien como intentos no plenamente filosóficos (híbridos teóricos) o bien como intentos de un signo filosófico insatisfactorio (llamémosle "naturalistas" por mor de la generalidad), lo que viene a resultar más o menos lo mismo. Hay una tercera alternativa que consistiría en sostener que aquellas teorías se ocupan de otros fenó- 
menos, relacionados pero diferentes, que no son ya acerca del significado, sino más bien acerca de los hechos que lo fundamentan. ${ }^{19}$ De esto se seguiría que el problema de la unidad proposicional estaría planteado y podría resolverse a nivel puramente semántico y que, en este nivel, sería posible defender una solución o disolución que resultará válida para las dimensiones invariables y literales de los significados asertivos.

Como vimos, ambas concepciones -la de Frege y la de Davidsonrelacionan este problema y su solución con la propiedad de las oraciones de ser verdaderas (o falsas). Aquí se podría plantear la segunda pregunta: ¿en qué medida sería explicativamente más adecuado considerar que la propiedad de ser verdaderas o falsas (ya sea considerada como una propiedad semántica sustantiva, ya sea sólo como un predicado que presta el servicio instrumental de elucidar el significado) no tiene prioridad explicativa o elucidatoria sobre un rango más amplio de otras propiedades semánticas y sobre otro tipo de emisiones? O, si se prefiere: ¿no podrían explicarse mejor los mismos fenómenos semánticos a partir de la consideración de una variedad de actos de habla, sin conceder primacía a los actos de habla asertivos? Algunos filósofos han dado una respuesta positiva a estas preguntas, cuestionando de diversas maneras la centralidad concedida a las aserciones. Entre ellos, vale la pena volver la atención hacia los múltiples puntos de ataque elegidos por Wittgenstein en sus Investigaciones Filosóficas: ni todas las oraciones están compuestas sólo por nombres (nombres de particulares y nombres de propiedades), ni todos los nombres de particulares significan del mismo modo (por ejemplo, los nombres propios) (\#79), ni todas las oraciones poseen la misma estructura gramatical y sintáctica (cfr. \#23 y \#27). Así, el modo indicativo que es característico de las oraciones asertivas, aquellas que tienen la forma "Las cosas estás así o asá", sirve para realizar actos de habla muy diferentes, p.e., no sólo para aseverar literalmente (presentar a una proposición como siendo verdadera), sino también para conjeturar, presuponer, declarar, dar a entender, insinuar, etc. En ciertos contextos ("contextos de cancelación") pueden también expresar una ironía o relatar una ficción (\#22).

En el mismo sentido, no todas las oraciones significativas tienen la estructura sintáctica ni semántica requeridas para ser analizadas en

${ }^{19}$ Uso aquí la distinción que propone Speaks (2016) entre "teorías semánticas" y "teorías fundacionales del significado". Mientras las teorías de Frege y Davidson deberían ubicarse en el primer grupo, los enfoques de Grice y del segundo Wittgenstein, entre tantos otros, corresponderían claramente al segundo grupo. Nótese, sin embargo, como señala Speaks, que Davidson también tiene algo que decir sobre los aspectos que fundamentan el significado. 
términos de unidades compuestas por tipos diferenciados de elementos sub-oracionales, por lo que el problema respecto de ellas ni siquiera podría plantearse, vgr. “iAuxilio!”, “No!”, “Fuera!” (\#27) ${ }^{20}$. Del mismo modo, tampoco se requiere que estas "expresiones incompletas" estén de algún modo "completas" y previamente presentes en la mente de quien habla, como si todas las expresiones usadas significativamente fueran 0 bien oraciones articuladas o bien oraciones sintáctica o semánticamente elípticas (\#19, \#20). Algunas expresiones que no poseen estructura oracional, emitidas bajo ciertas condiciones, pueden ser actos de habla completos (p.e., los usos de los nombres propios en las órdenes, las instrucciones y las exhortaciones; también el acto de habla de llamar a alguien, o el de saludar, que sólo refiere a la persona a quien se saluda sin atribuirle propiedad alguna, etc.) (\#27).

Además, no es necesario para realizar los mismos actos de habla que los recursos gramaticales de una lengua, por ejemplo, según "un determinado modelo de nuestra gramática", sean iguales o similares a los empleados por otras lenguas (\#19 y \#20). Así, tampoco sería posible identificar tipos de emisiones lingüísticas más básicas, las aserciones, respecto de las cuales el problema de la unidad proposicional pudiera ser analizado o explicado. Dicho de otra manera, "la forma general de la proposición” (\#65, \#108, \#114, \#134) no sería una entidad teórica útil, porque las emisiones lingüísticas no poseen significado en virtud de su forma, sea esta gramatical, sintáctica o semántica ${ }^{21}$. Dado "que hay innumerables géneros diferentes de empleo de todo lo que llamamos «signos», «palabras», «oraciones»" (\#23), y que "hacemos las cosas más heterogéneas con nuestras oraciones" (\#27), el problema de la unidad proposicional no puede plantearse, no al menos en el formato clásico, para muchos usos significativos del lenguaje. Incluso si las oraciones emitidas poseyeran la estructura oracional canónica que favorece su examen, este también debería orientarse hacia una reconstrucción o elucidación singularizada de sus usos, constreñida por la atención a

${ }^{20} \mathrm{El}$ ejemplo del juego de lenguaje de los albañiles en Investigaciones Filosóficas \#2, que sólo cuenta con cuatro palabras usadas para realizar actos de habla no asertivos, como órdenes o pedidos, señala el mismo fenómeno (cfr. Kemp, 2011),

${ }^{21}$ Por cierto, filósofos con muy diferentes visiones sobre el significado también han reconocido este tipo de fenómenos: los mismos tipos sintácticos de oraciones, vgr. en modo indicativo, interrogativo, imperativo, sirven para realizar muy diferentes actos de habla. Sin embargo, o bien asignan a estos fenómenos una importancia secundaria, o bien ofrecen una explicación de signo contrario a la que sugiere Wittgenstein, anclada en el uso. Davidson (1979), por ejemplo, hace una propuesta muy diferente a la sugerida por Wittgenstein, y también diferente a la de Frege, sobre cómo entender estos desacoplamientos entre los modos sintácticos y los tipos de emisiones. 
las circunstancias relevantes y a las reglas de las prácticas en las que ocurren, dado que la misma forma sintáctica y semántica podría ser usada para realizar muy diferentes actos de emisión.

Podría pensarse, no obstante, que todas las oraciones no declarativas son susceptibles de ser transformadas en oraciones declarativas, por ejemplo, podemos transformar una pregunta "...en una descripción de mi estado mental de incertidumbre" (\#24). Este tipo de operaciones que, según Wittgenstein, derivan de "la tendencia a sublimar la lógica de nuestro lenguaje" (\#38), descansa en un supuesto objetable: "(C)como si sólo hubiera una cosa que se llama: «hablar de cosas» ... (cuando) en realidad hacemos las cosas más heterogéneas con nuestras oraciones" (\#27).

Según el hilo de estas consideraciones, las oraciones declarativas no son el "downtown" del language (\#18) y la aserción no expresa la función esencial del lenguaje o, lo que es igual, no tiene primacía sobre otras funciones (Wolf, 2019). El conjunto de estas observaciones pareciera llevarnos a concluir que no hay una materia suficientemente unificada sobre la que efectuar un análisis teórico (Wolf, 2019) y que, en consecuencia, Wittgenstein sólo estaría sumando fundamentos para desalentar la posibilidad de una reflexión sistemática sobre el significado lingüístico. No obstante, un efecto positivo de esta estrategia es la ampliación del foco de la atención filosófica sobre un sinnúmero de expresiones significativas que no parecen adecuarse ni a las restricciones formales clásicas ni a la preeminencia concedida a los actos de habla asertivos, y menos aún, sólo a sus productos: las aserciones.

Estas observaciones dispersas no cuentan, ni consideradas independientemente ni en conjunto, como una objeción a los enfoques del estilo Frege-Davidson, sino sólo señalan que la cuestión acerca de cuáles sean las operaciones básicas que realizamos con el lenguaje (cognitivas, pragmáticas, semánticas), sobre la base de las cuales explicar su empleo, podría asentarse en una heterogeneidad irreductible de tipos de casos. Esta heterogeneidad podría, por una parte, relativizar el problema de la unidad proposicional a un grupo importante de ellos y, adicionalmente, favorecer (o requerir) respuestas diferenciadas para los restantes casos, o bien podría conducir a la adopción de un enfoque teórico de otro tipo para dar cuenta apropiadamente de la nueva unidad de análisis: los actos de emisión lingüística, bajo una concepción diferente del lenguaje, el lenguaje como un medio de comunicación, en el sentido apuntado por Strawson.

Como señala Moretti, las concepciones del significado de Frege y Davidson buscan explicar o esclarecer las peculiaridades del lenguaje cognoscitivo o con pretensiones cognoscitivas, lo que supone privilegiar la 
"práctica argumentativa" (LS, p. 32): los actos asertivos que la componen y las reglas de inferencia que los vinculan. Esta visión depende de adoptar un enfoque del lenguaje como medio de representación, o, si se prefiere, de poner el foco en sus funciones representacionales y cognoscitivas, un enfoque que se mantiene, aunque en otro formato, en la teoría de Davidson. En contraste, las concepciones del lenguaje centradas en la comunicación, por diversas razones que no pueden exponerse aquí, están más dispuestas a admitir una heterogeneidad de vehículos y estructuras para una amplia variedad de propósitos. En consecuencia, pueden hacer lugar a la existencia de parentescos y semejanzas entre nuestros usos lingüísticos y nuestros usos de otros tipos de sistemas semióticos también simbólicos, tanto naturales como artificiales, que también poseen propiedades semánticas ${ }^{22}$. En el marco de este tipo de concepciones, cabe esperar que ya no estemos ante un mismo problema fundamental, el problema de la unidad proposicional, y que, como consecuencia, la "solución" buscada, como se señaló antes, tampoco pueda ser unitaria.

Como se ocupa de mostrar Moretti con cierto detalle en éste y otros trabajos, ambas concepciones, LR y LI, asignan un papel especial a la lógica, o bien "urdiendo la trama" o bien "representando conexiones necesarias entre los hechos" (LS, p. 36). Moretti distingue entre la "lógica" como teoría de la inferencia en el uso del "lenguaje común" con fines cognoscitivos, y la Lógica o los "sistemas de lógica" como estructuras matemáticamente definidas aplicadas a "lenguajes formales" o "estructuras sintácticas artificiales" (LS, p. 33). En "Concepciones de la lógica" se distinguen una manera sintáctica de otra manera semántica de caracterizar la relación de consecuencia lógica de la que se ocupa la Lógica (pp. 166-170). Pero, además, si no entiendo mal, ambas concepciones conducen, aunque por caminos diferentes, a perspectivas similares sobre el papel de la lógica (en el sentido de las reglas y principios lógicos que operan en la práctica lingüística) y sobre el carácter de la Lógica (en el sentido de la reflexión sistemática sobre las reglas y principios lógicos).

Frege, como bien señala Moretti (LTC, p. 20), anticipó una manera de tratar el carácter especial, no teórico, de la Lógica proponiendo la distinción entre decir y mostrar, que luego Wittgenstein, el primero, convirtió en una herramienta estructural de su propia concepción lógico-semántica o de su visión "trascendental" de la lógica (LS, p. 43). Por su parte, al asumir desde el inicio una perspectiva trascendental,

\footnotetext{
${ }^{22}$ Para una interpretación como ésta, de raigambre wittgensteineana, cargada de interesantes sugerencias y matices, véase $\operatorname{Kemp}$ (2011, pp. 19-22).
} 
Davidson estaría también afirmando que los principios constitutivos de la inteligibilidad (o de la interpretabilidad) de todo lenguaje, incluidos los principios lógico-semánticos que lo estructuran, no pueden ser objeto de una teoría, en ningún sentido genuino (es decir, "intramundano") del término, sino que sólo poseen una "función mostrativa" que consistiría en "disponer a una cierta experiencia peculiar inefable" (LTC, p. 21).

En más de una ocasión, Moretti se refiere a la tarea de la Lógica como la de proporcionar "explicitaciones" de las normas aceptables o "de presupuestos para toda aseveración" (LS, p. 33-34). Moretti dice mucho acerca de este problema, el de la indecibilidad teórica de la Lógica (LTC, p. 20), apuntando a señalar, si no me equivoco, que los principios básicos (sean cuales fueren y aun pudiendo no tener todos el mismo alcance ni ser por necesidad siempre los mismos, e incluso pudiendo regir distintos principios para distintos sub-lenguajes) son trascendentales. Pero, dado que, según también se afirma, ya no serían la expresión de un orden único, necesario y a priori del mundo, serían principios lógicos específicos cuya "aceptabilidad es siempre empíricamente disputable y evaluable en términos de un criterio de ajuste a la experiencia intersubjetiva, necesariamente abierto" (LTC, p. 19). Por lo tanto, podría interpretarse que, antes bien, se trata principios "modestamente trascendentales"23, esto es, que pueden entenderse en términos de rasgos estructurales de nuestro esquema conceptual, que "sólo" especifican los límites de una "concebibilidad revocable", esto es, "limitaciones implícitamente determinadas por un rango de prácticas disponibles...”, que podrán variar de acuerdo con distintas contingencias empíricas ${ }^{24}$. Caracterizar a los lenguajes como "entes históricos o culturales" (UP, p. 71) (y no como estructuras abstractas permanentes) parece hacer lugar a la tesis de que sus "lógicas" también lo son, en algún grado. Dado que las ocasiones en las que Moretti emplea el término "trascendental" (y su equivalente "condiciones de posibilidad") no son acompañadas de mayores especificaciones, podríamos preguntarnos si esta interpretación es compatible con su perspectiva de los principios y verdades de la lógica (sean cuales fueren). En relación con el mismo punto, también cabría preguntar, además, si aquello que muestran las reglas y principios lógicos, pero no pueden decir, son las maneras aceptadas de operar con el "simbolismo", no ya objetos o "super-hechos" susceptibles de conocimiento "teórico" (o "super-teórico") de algún tipo. Dicho de otra forma, la Lógica, o mejor,

\footnotetext{
${ }^{23}$ Stroud (1968) elabora el concepto de "argumento trascendental modestamente interpretado".

${ }^{24}$ Sacks (2000, p. 213).
} 
las Lógicas específicas, al tener un carácter normativo peculiar, al ser constitutivas de nuestras maneras de aseverar y razonar, podrían ser reconstruidas como versando sobre un conjunto de capacidades, técnicas y herramientas para pensar y hablar, no como un conjunto sustantivo de "verdades inefables" ¿'¿Acepta Moretti esta interpretación, que también podría denominarse 'modesta', de la lógica (y de la Lógica)? Al parecer, esto mismo se afirma en LS: "Su función será la de instrumentos para perfeccionar la competencia en el manejo del discurso teórico" (p. 36).

En cuanto a la importancia de una reflexión ontológica específica para una estrategia como la davidsoniana, que practica una evidente abstinencia metafísica en su explicación de la unidad proposicional, Moretti sugiere que no sólo sería compatible con ella (UP, 73), sino que su solución al problema no requiere de una posición anti-metafísica, o mejor aún, no supone "que carezca de sentido, o que no sea legítimo pensar estructuras mundanas (pensar cómo es el mundo)", y luego intentar relacionarlas con nuestras estructuras lingüísticas (UP, p. 73). Ahora bien, Moretti sugiere la necesidad de integrar semántica y ontología “... cuando interpretante y cognoscente se identifican" (UP, p. 73), porque entonces es evidente que está presupuesta una estructura mundana vinculada con las prácticas interpretativas, que están presupuestos el "nexo intérpretes-mundo" o "la relación ser-con-otros-y-con-cosas" como una estructura constitutiva del lenguaje. Pero, como se dijo, esto es así sólo "cuando interpretante y cognoscente se identifican".

Hay mucho más en UP, mucho más que lo que Frege y Davidson dijeron, más también que lo que Fregidson ${ }^{26}$ afirma por boca de Moretti. Ahora bien, más allá del indudable interés filosófico (no meramente histórico) que tienen los parecidos, diferencias y confluencias entre ambos filósofos, Moretti agrega una idea que no encontramos ni en Frege ni en Davidson. Me refiero a la idea de una estructura conformada por la comunidad de hablantes, el sistema lingüístico y "la trama de las cosas".

${ }^{25}$ Kremer (2002), examinando la distinción entre decir y mostrar en el Tractatus, propone una interpretación "resuelta" de la carencia de sentido de las proposiciones lógicas (y matemáticas) que muestran "la forma lógica del mundo", en el sentido en que sólo manifiestan una técnica para usar (y comprender) proposiciones significativas o para realizar inferencias (pp. 297 y ss.).

${ }^{26}$ Kripkenstein es una figura bastante conocida (el Wittgenstein de Kripke). Existe también un menos conocido Fregenstein (una cierta manera de interpretar el influjo de Frege sobre Wittgenstein). Creo que Moretti ha identificado en sus escritos a un tal Fregidson: sugiero bautizar así al filósofo que surge de la convergencia entre algunas ideas de Frege y de Davidson según la interpretación desarrollada por Moretti, y que es tanto una reconstrucción como una expansión de lo que ambos filósofos dijeron, vistos desde las cuestiones que preocupan y en las que piensa Moretti, desde hace años. 
Esa estructura puede ser "objetivada" o "pensada sustantivamente" y, por lo tanto, "naturalizada". Pero si, en cambio, es vista como aquello presupuesto por el habla, revelando nuestra constitución esencialmente lingüística y también las condiciones de posibilidad de la objetividad, esto es, si la relación de ser-con-otros-y-con-cosas (UP, p. 74) es una estructura trascendentalizada (aunque 'deskantianizada' al quedar privados por este giro interpretativista de la posibilidad de "pensar" un mundo "en sí") (UP, p. 72), entonces esa estructura ofrecería el fundamento inefable de la unidad proposicional. Ahora bien, sobre esa estructura no es posible, por razones lógicas, ni preguntar ni afirmar nada. La frase que elegí como título a este comentario, "Somos criaturas de la lógica y no del silencio", expresa un núcleo importante de las ideas expresadas en UP. Ese núcleo podría resumirse así: "Eliminar todo principio lógico sería tanto como prescindir del lenguaje" (CL, p. 180), y prescindir del lenguaje pareciera un objetivo humanamente imposible (cfr. CL, p. 163). Bajo esa perspectiva, que es la de Moretti, el problema de la unidad proposicional sería visto, a la postre, como un problema lógico, en el que tanto la condición humana constituida por el lenguaje como lo que la trasciende, sirven de continente y también de límite a la reflexión filosófica y a su articulación verbal. ${ }^{27}$

\section{Bibliografía}

Bronzo, S. (2017). Frege and propositional unity. British Journal for the History of Philosophy 4, 750-771.

Davidson, D. (1967). Verdad y significado. En su De la verdad y de la interpretación (pp. 39-56). Gedisa.

Davidson, D. (1979). Modos y ejecuciones. En su De la verdad y de la interpretación (pp. 123-134). Gedisa.

Davidson, D. (2005). Truth and predication. The Belknap Press of Harvard Univ. Press.

Dennett, D. (1996). Kinds of minds. The Orion Pub. Group.

Dummett, M. (1973). Frege's philosophy of language. Harper \& Row.

Frege, G. (1892a). On concept and object. En M. Beaney (Ed.), The Frege Reader (pp.181-193). Blackwell.

Frege, G. (1892b). Comments on Sinn and Bedeutung. En M. Beaney (Ed.), The Frege Reader (pp. 172-180). Blackwell.

Frege, G. (1923-26) Logical Investigations III. En Collected Papers on

\footnotetext{
${ }^{27}$ Agradezco la atenta lectura y las valiosas sugerencias de Eleonora Orlando a una versión previa de este comentario.
} 
Mathematics, Logic, and Philosophy. Editado por B. McGuinness y traducido por M. Balck et al., Blackwell, 1984.

García-Carpintero, M. (2010). Gaskin's ideal unity. Dialectica, 64(2), 279-288.

Gaskin, R. (2008). The unity of the proposition. Oxford University Press.

Gibson, M. I. (2004). From naming to saying: the unity of the proposition. Blackwell.

Glock, H-J. (2010) ¿Qué son los conceptos? En M. Aguilera, L. Danón \& C. Scotto (Eds.), Conceptos, lenguaje y cognición (pp. 47-87). Editorial UNC.

Hanks, P. (2017). Proposition, synonymy, and compositional semantics. En F. Moltmann \& M. Textor (Eds.), Act-based conceptions of propositional content. Contemporary and historical perspectives (pp. 235-253). Oxford University Press.

Hylton, P. (2005). Propositions, functions and analysis: selected essays on Russell's philosophy. Oxford University Press.

Jolley, K. D. (2007). The concept 'horse' paradox and Wittgensteinean conceptual investigations. A prolegomenon to Philosophical Investigations. Ahsgate Pub.

Kemp, G. (2011). The unity of the proposition in the later Wittgenstein. Conceptus, 97, 7-28.

King, J. C. (2014). What role do propositions play in our theories? En J. King, S. Soames \& J. Speaks (Eds.), New thinking about propositions (pp. 5-8). Oxford University Press.

Kremer, M. (2002). Mathematics and meaning in the Tractatus. Philosophical Investigations, 25(3), 273-303.

Merricks, T. (2015). Propositions. Oxford University Press.

Moretti, A. (1992). Semántica tarskiana, lenguaje natural y ontología. En su Interpretar y Referir. Ejercicios de análisis filosófico (pp. 11-30). Grama Ediciones.

Moretti, A. (2006). Lógica y semántica. Revista de filosofía, 31(2), 31-43.

Moretti, A. (2010). Concepciones de la lógica. Páginas de filosofía, 11(23), 162-185.

Moretti, A. (2014). La unidad proposicional. Avatares filosóficos, 1, 6275.

Moretti, A. (2016). La lógica y la trama de las cosas. Ideas y valores. Revista colombiana de filosofía, 65(161), 5-22.

Orlando, E. (2015). El desafío contextualista y el debate en torno al relativismo de la verdad. En E. Orlando (Ed.), Significados en contexto y verdad relativa. Ensayos sobre semántica y pragmática (pp. 15-39). Título. 
Peacock, H. (2011). Is there a problem about propositional unity? Dialectica, 63(3), 393-418.

Platón (1970. Sofista. Instituto de Estudios Políticos. Trad. A. Tovar.

Ryle, G. (1960). Letters and syllables in Plato. En Collected Papers, volume 1, chap. 3 (pp. 57-75). Routledge.

Sacks, M. (2000). Objectivity and insight. Clarendon Press.

Soames, S. (2012). Propositions. En G. Russell \& D. G. Fara (Eds.), Routledge Companion to Philosophy of Language (pp. 209-220). Routledge.

Soames, S. (2017). For want of cognitively defined propositions. A history of insights and missed philosophical opportunities. En F. Moltmann \& M. Textor (Eds.), Act-based conceptions of propositional content. Contemporary and historical perspectives (pp. 181-208). Oxford University Press.

Speaks, J. "Theories of meaning". En E. N. Zalta, The Standford Encyclopedia of Philosophy. http://plato.stanford.edu/archives/ fall2017/entries/meaning.

Speaks, J. (2019). Cognitive acts and the unity of proposition. Australasian Journal of Philosophy, 98(4), 646-660.

Strawson, P. (1970). Meaning and truth. En sus Logico-linguistic papers (pp. 171-189). Methuen \& Co.

Stroud, B. (1968). Trascendental arguments. Journal of Philosophy, 65, 241-6.

Wittgenstein, L. (1921). Tractatus logico-philosophicus. Gredos.

Wittgenstein, L. (1953). Investigaciones Filosóficas. Crítica.

Wolf, M. P. (2019). Making sense of the role of assertions. Philosophical Investigations, 42(4), 396-418.

Zalabardo, J. (2017). Davidson, Russell and Wittgenstein on the problem of predication. En C. Verheggen (Ed.), Wittgenstein and Davidson on thought, language and action (pp. 226-249). Cambridge University Press. 